\title{
A leitura da dinâmica social moderna em um contexto de globalização: sistemas abstratos e o desencaixe entre tempo e espaço como produção de mal-estar e sofrimento
}

\author{
The modern social dynamics reading in a context of globalization: abstract \\ systems and the undock between time and space as production of malaise and \\ suffering
}

José Francisco Dias da Costa Lyra

Doutor em Direito pela Universidade do Vale do Rio dos Sinos - UNISINOS Juiz de Direito e Professor titular do Programa de Pós-Graduação Stricto Sensu em Direito Doutorado e Mestrado e da Graduação em Direito da Universidade Regional Integrada do Alto Uruguai e das Missões - URI, Santo Ângelo/RS jfdclyra@tjrs.jus.br

\begin{abstract}
(D) Lara Narjana Johann Mestra em Direitos Especiais pela Universidade Regional Integrada do Alto Uruguai e das Missões URI, Santo Ângelo/RS Pós-Graduada em Direito Processual Civil e Temas Relevantes do Direito Civil - Faculdades Integradas Machado de Assis. Advogada e Assessora Jurídica Municipal laranjohann@hotmail.com
\end{abstract}

Resumo: A presente pesquisa diz respeito ao fenômeno da globalização na modernidade e seus reflexos no meio social e nas relações interpessoais. Através de uma pesquisa bibliográfica, procurou-se descrever, primeiramente, o fenômeno da globalização e suas contribuições à dinâmica social moderna. Ainda, a pesquisa buscou estudar as noções de desencaixe entre tempo e espaço, de Anthony Giddens, e a possibilidade de deslocamento de acontecimentos locais, numa perspectiva global, além de trazer à discussão a relação de confiança estabelecida entre sistemas abstratos e o indivíduo. Feito isso, o trabalho abordou a insegurança do indivíduo diante de todo o fenômeno da globalização inaugurado com a modernidade. Nesse sentido um risco é percebido pelo indivíduo, pois em seu projeto reflexivo pela busca da formação do eu, o indivíduo confia nos sistemas abstratos parte da formação da auto identidade e, num diálogo com o entendimento de Christian Dunker, novas formas de sofrimento são instauradas.

Palavras-chave: tempo e espaço; desencaixe; sistemas abstratos; mal-estar; sofrimento.

Abstract: This research concerns the phenomenon of globalization in modernity and its effects on the social environment and on interpersonal relationships. Through a bibliographic search, we sought to describe, first, the phenomenon of globalization and its contributions to modern social dynamics. Still, the research sought to study Anthony Giddens' notions of separation between time and space, and the possibility of displacing local events, in a global perspective, in addition to bringing to the discussion the relationship of trust established between abstract systems and the individual. That done, the work addressed the individual's insecurity in the face of the whole phenomenon of globalization inaugurated with modernity. In this sense, a risk is perceived by the individual, because in his reflective project in the search for the formation of the self, the individual trusts in the abstract systems part of the formation of self-identity and, 
LYRA, José Francisco Dias da Costa; JOHANN, Lara Narjana. A leitura da dinâmica social moderna em um contexto de globalização: sistemas abstratos e o desencaixe entre tempo e espaço como produção de

in a dialogue with the understanding of Christian Dunker, new forms of suffering are established.

Keywords: time and space; undock; abstract systems; malaise; suffering.

\section{Para citar este artigo}

ABNT NBR 6023:2018

LYRA, José Francisco Dias da Costa; JOHANN, Lara Narjana. A leitura da dinâmica social moderna em um contexto de globalização: sistemas abstratos e o desencaixe entre tempo e espaço como produção de mal-estar e sofrimento. Prisma Jurídico, São Paulo, v. 20, n. 2, p. 238-255, jul./dez. 2021.

http://doi.org/10.5585/prismaj.v20n2.18215.

\section{Introdução}

Não se permite mais a separação do estudo do indivíduo - atributo que se encarrega a psicologia - e o da sociedade - cujos encarregados são sociólogos e filósofos -, uma vez que indivíduos compõem a sociedade e ela se faz presente no indivíduo. Dito isso, é relevante a abordagem do presente esboço na medida em que se estabelecem alguns pontos argumentativos a respeito da atual dinâmica social. A sociedade sofreu consideráveis mudanças com o advento da tecnologia e da comunicação em rede, e fez surgir também diversas formas de sociabilidade através da tela de smartphones e laptops. Novas formas de trabalho surgiram e com elas o avanço do consumo através da era capitalista e do imediatismo consolidados.

Como principal ponto, tem-se que a modernidade produziu novas representações sociais bem como alterou as narrativas de sofrimento, principalmente nos processos modernos de produção. Preponderam nas atuais representações sociais o capitalismo e o consumo, e com essa nova dinâmica social o indivíduo vê sua autonomia relativizada. Os fluxos econômicos resultam dos diversos contatos na perspectiva global. Entretanto, considerações devem ser feitas acerca dos reflexos da modernização no indivíduo e como as novas formas de sofrimento vem refletindo. Percebe-se que os processos de alongamento pelo fenômeno da globalização e do afastamento da dinâmica entre tempo e espaço, em que eventos locais surtem efeito em um contexto global, bem como os sistemas abstratos da sociedade moderna trouxeram juntamente insegurança e risco ao indivíduo. Os processos de formação de auto identidade, hoje, são fundados no receio de que tais sistemas abstratos não funcionem da forma que se espera que funcionem, e o risco de eventos sazonais conduzem o indivíduo à produção de insegurança quanto ao futuro e à sua capacidade de reagir aos fenômenos externos ao seu controle em meio à modernidade. 
LYRA, José Francisco Dias da Costa; JOHANN, Lara Narjana. A leitura da dinâmica social moderna em um contexto de globalização: sistemas abstratos e o desencaixe entre tempo e espaço como produção de

Cada vez mais, são buscados atrativos a fascinar o espectador por muito mais tempo, em meio a um mercado acirrado de entretenimento digital. No mesmo sentido, a dinâmica social atual apresenta uma acentuada e crescente forma de sofrimento, baseada em forma de condomínio, isto é, por muros ou barreiras de isolamento. Com isso, são criados novos formatos de aproximação e de distanciamento, mesmo que ainda não se tenha a convicção dos reais impactos nas relações sociais. O afastamento entre tempo e espaço somente é instituído com a modernidade, bem como o risco se insere nas incertezas geradas pela globalização.

Como problema norteador da pesquisa, pergunta-se: quais implicações surgiram com o desencaixe entre o tempo e espaço bem como a criação de sistemas abstratos e quais os seus efeitos para as relações interpessoais e do indivíduo consigo? Em busca de possíveis respostas à pergunta delimitadora, utilizar-se-ão obras que, entende-se, conversam entre si quanto à temática envolvendo a sociedade moderna. Assim, a pesquisa será realizada através do método hipotético-dedutivo, numa análise qualitativa dos dados, por meio de pesquisa bibliográfica. Para tanto, será desenvolvida a análise em três seções, sendo que a primeira será abordado o fenômeno da globalização em consonância com os tempos "líquidos"; após, serão anotadas noções sobre o desencaixe entre tempo e espaço, à luz do conhecimento sociológico; para por fim, indagar sobre o mal estar e o cansaço como experiências de risco do mundo moderno.

\section{$2 \mathrm{O}$ fenômeno da globalização e os tempos de liquidez}

A globalização se reflete em todo o cotidiano humano. Ela é uma ordem global e por isso, é necessária sua discussão neste tópico, eis que inerente a quase todas as sociedades. Criada em lugar algum, mas disseminada em todos os cantos, ela é entendida como um mundo único e revolucionário, ocorrência incontrolável. Fenômeno não somente característico da economia, pois afeta também a política, os meios tecnológicos e culturais. É um processo de alongamento (GIDDENS, 1991, p. 60), em relações sociais entre eventos locais e distantes, e essas relações se intensificam numa escala mundial. Bauman esforçou-se em conceituá-la, ainda que se ativesse à capacidade de controle dos estados, esboça a perspectiva no sentido de:

[...] lembrar que o conceito de "globalização" foi cunhado para substituir o há muito estabelecido conceito de "universalização", quando se tornou aparente que a emergência de vínculos e redes globais não tinha nada da natureza intencional e controlada implícita no velho conceito. A "globalização" indica os processos vistos como auto-impulsionados, espontâneos e erráticos, sem ninguém sentado à mesa de controle ou planejando, muito menos se encarregando dos resultados finais. Podemos dizer, sem muito exagero, que o termo "globalização" se refere à natureza desordenada dos processos que ocorrem acima do território "principalmente coordenado" e administrado pelo "mais alto nível" do poder institucionalizado, isto é, Estados soberanos. (BAUMAN, 2008, p. 48). 
LYRA, José Francisco Dias da Costa; JOHANN, Lara Narjana. A leitura da dinâmica social moderna em. um contexto de globalização: sistemas abstratos e o desencaixe entre tempo e espaço como produção de mal-estar e sofrimento

Notadamente, seus efeitos são encontrados em todos os aspectos da vida humana, não possui ordem, formato ou formas de controle. O fenômeno atingiu a todos e evidencia a sua força de submissão e dependência. Ele pode fortalecer ou criar identidades culturais e pode criar novas zonas econômicas e culturais, expressa ser uma contínua mudança comportamental. Segundo Giddens, um dos grandes propulsores dessas alterações é o sistema financeiro global que foi moldado pela tecnologia e pela comunicação entre as culturas. (GIDDENS, 2006).

Sua principal característica - e que está em constante solidificação - é a não concentração perpétua do controle nas mãos de uma entidade, grande empresa ou nação. E admite-se falar em uma unificação humana, em uma sociedade cosmopolita global. (GIDDENS, 2007, p. 28). Mesmo que sejam diversas as culturas, os hábitos, as estruturas, os comportamentos, etc., o fenômeno da globalização aproximou as diferenças, pois alterou significativamente a perspectiva de tempo, espaço e poder. Quer dizer, a globalização estabeleceu uma ligação entre cultura e economia, e estabeleceu que cultura, comunicação, construção de conhecimento são meios de produção ao mesmo tempo em que produtos (ORTIZ, 2008).

O sentido de soberania não é o mesmo de outrora, o poder deixou de ser do rei, único, mas isso não quer dizer que não exista a transitória centralização de poder nas mãos de quem possua a grande parte do capital. E nem que o capital não flutue diante do fenômeno da globalização. Existe um poder flutuante capaz de ser transponível, mas por não ser absoluto e perpétuo, nessa transposição, explora e abandona inclusive as consequências de sua exploração. Significa dizer que "os custos de se arcar com as consequências não precisam agora ser contabilizados no cálculo da 'eficácia' do investimento”. (BAUMAN, 1999, p. 16).

As práticas sociais também acabam por ser constituídas em torno de valores culturais e modos de vida que vão além de interesses de classes, e fazem oposição à verticalização e rigidez de organização e comunicação, que, segundo Ortiz, são consubstanciados pela rede organizacional e comunicativa, pela Cibercultura, e provoca mudança de atitude em movimentos que se popularizam e ganham corpo pela internet. A identidade cultural se mescla e entra em uma esfera global, com potencial para a criatividade social, mas também ambígua e confusa (ORTIZ, 2008).

Em Giddens, é possível encontrar ponderações importantes acerca da globalização, pois ele propõe ao leitor a reflexão das consequências da modernidade, na qual a globalização possui importante vinculação. Com a globalização as relações sociais se intensificam em escala mundial, pois fenômenos ocorridos em um canto do planeta não são somente percebidos, mas 
LYRA, José Francisco Dias da Costa; JOHANN, Lara Narjana. A leitura da dinâmica social moderna em um contexto de globalização: sistemas abstratos e o desencaixe entre tempo e espaço como produção de

modelados por outros que ocorrem no outro canto. (GIDDENS, 1991). As barreiras fronteiriças físicas acabaram por perder o sentido de existência.

Como ordem econômica, o capitalismo contribuiu para a globalização, em que Giddens o confere a quarta dimensão da globalização; é o capitalismo que delimita e condiciona a ordem econômica mundial. Juntamente com o capitalismo, e como figura principal de solidificação, a tecnologia responsabilizou-se em intensificar as comunicações através de comunidades informacionais ou virtuais, sem necessidade de deslocamento do indivíduo até as redes, vez que são elas que envolvem os usuários em conexão, em uma cultura nômade de conectividade (LEMOS, 2004). Dito isso, as fronteiras territoriais são suplantadas pelo tempo da comunicação, e são encolhidas pelas mensagens instantâneas e pela facilidade das tecnologias, que aproximam o espectador. (BAUMAN, 1999).

Neste sentido, tem-se a Cybercultura, isto é, "o conjunto de técnicas (materiais e intelectuais), de práticas, de atitudes, de modos de pensamento e de valores que se desenvolvem juntamente com o crescimento do cyberespaço" (LÉVY, 1999, p. 17), representa muito mais do que a integração e conexão entre o comportamento humano e as tecnologias, já que também diz respeito aos novos anseios de laços sociais que vão além das barreiras do espaço físico, emancipadas de instituições de poder, e que se fundam em um mesmo interesse de cooperação e colaboração. (SALDANHA; SALDANHA, 2017, p. 37). Assim, verifica-se que nos últimos anos ocorre, culturalmente, uma mutação totalizante de alcance geral.

Se por um lado a globalização permite ultrapassar barreiras com a comunicação, por outro o capitalismo permite o domínio da economia mundial por um pequeno grupo de corporações. Ao existir dependência de produção para a obtenção de lucro, as grandes corporações transformam a força de trabalho em mercadoria, o que implica em desigualdades em esfera global. (GIDDENS, 1991). Ademais, a liquidez encontrada nos escritos de Bauman confere à sociedade atual a rapidez das relações, a aproximação através das redes, mas uma incapacidade de controle de ordem dos fenômenos:

Assim como nenhuma tentativa de acomodar a complexidade do mundo em divisões definidas e compreensivas parece ter chance de sucesso, também não parece provável que a ambivalência seja vencida e deixe de assombrar os que buscam por segurança. Pelo contrário, quanto mais intenso é o desejo por ordem e mais frenéticos são os esforços para instaurá-la, maior será o volume de restos ambivalentes e mais profunda a ansiedade que eles irão gerar. Existe pouca chance de que a construção da ordem chegue algum dia ao fim, sendo uma preocupação auto-impulsionada e autointensificadora que ricocheteia em uma atividade autodestrutiva. (BAUMAN, 2008, p. 47) 
LYRA, José Francisco Dias da Costa; JOHANN, Lara Narjana. A leitura da dinâmica social moderna em um contexto de globalização: sistemas abstratos e o desencaixe entre tempo e espaço como produção de mal-estar e sofrimento

Influências globalizantes também se inserem nos aspectos íntimos da vida humana. Há uma transformação no que diz respeito à dinâmica das relações sociais e da sua rapidez em se dissolver. Bauman entende que uma alteração na concepção do matrimônio passando a prevalecer a expectativa de se viver junto, tornando as relações transitórias. (BAUMAN, 2008, p. 37). Na mesma rapidez, proporção e intensidade que as relações se solidificam, elas se diluem; libertou-se, de certa forma, das regras imutáveis antes sobrepostas.

Significa dizer que o objetivo das relações íntimas supera o interesse de castas e o desejo de prolongação da vida; elas se emancipam das amarras religiosas e do culto a um Deus que proíbe e se vinculam à crença de uma união fundada no afeto, de um deus que permite, e, então a dissolubilidade dessas relações restou muito mais prática e acessível. E, tal qual como ocorre nas relações matrimoniais, ocorre nas demais relações sociais (no que diz respeito ao trabalho, à ordem, à economia, etc).

De igual forma, se afirma que:

se de um lado temos a multiplicidade de informações e de acessos a novos sites e domínios, por outro lado é importante lembrar que uma das características dessa cibercultura - a velocidade, o constante fazer e desfazer -, choca-se com um dos aspectos da Cultura, que é o de sua permanência/duração. (ALMEIDA, 2010, p. 699).

Tal alternância, não significa que a cultura corrompeu-se, mas sim, teceu uma forma líquida e fluída de existência. Outras formas de relacionamento surgem pela possibilidade de mantê-los mesmo à distância, de comunicação on-line e off-line (ORTIZ, 2008). Giddens estabelece algumas características da modernidade, através da explicação da dialética entre tempo e espaço, em que não se exige o lugar como mediador. Nesse sentido, o alongamento do dinamismo de tempo e espaço é muito maior após a globalização. (GIDDENS, 1991).

A dinâmica entre tempo e espaço, oferecida pelos ensinamentos de Giddens pode trazer ao estudo, meios pelos quais poderá ser trabalhado esse questionamento. Em razão da evidente e inconteste alternância cultural pelos efeitos da globalização, foi possível identificar que, o imutável perdeu seu sentido, ante as aproximações facilitadas que ganharam espaço no novo contexto societário. Assim, partindo do pressuposto que houve mudanças significativas pelo advento da globalização, inclusive nas relações sociais (consigo e com os outros), bem como em relação às noções de tempo e espaço, se faz necessário, na próxima seção, trazer um olhar mais apurado ao fenômeno de desencaixe de tempo e espaço, que ganha forças diariamente. 
LYRA, José Francisco Dias da Costa; JOHANN, Lara Narjana. A leitura da dinâmica social moderna em um contexto de globalização: sistemas abstratos e o desencaixe entre tempo e espaço como produção de

mal-estar e sofrimento

\section{0 conhecimento sociológico: o desencaixe de tempo e espaço na modernidade}

Tendo perpassado alguns aspectos sobre a globalização, considerados essenciais para prosseguir com o estudo, em especial as mutações sociais que caracterizam essa quadra histórica, passa-se a expor considerações acerca do encaixe ou desencaixe entre as elementares: tempo e espaço. A modernidade é interpretada sob vários enfoques pelas ciências sociais. Anthony Giddens em suas observações acerca da compreensão da modernidade refere que ela possui em suas instituições várias dimensões e que os seus componentes elementares possuem algum papel (GIDDENS, 1991).

Nesse sentido, ele inicia o trabalho oferecendo ao leitor diferentes conceitos da sociologia, mais especificamente noções de "sociedade", como principal ponto do discurso sociológico. A sociedade apresenta uma noção ambígua, podendo ser uma associação social em sua forma genérica, como também a um sistema específico de relações sociais. O segundo conceito é utilizado para se referir a sistemas fechados de formação social. Citando desde Marx, da compreensão do capital e a exploração do homem sobre o homem, a Durkheim com o seu super-ser, Giddens refere a aceitação pacífica de que a sociologia tem como ponto fundamental de estudo a sociedade. (GIDDENS, 1991).

Para Talcoltt Parsons, conforme Giddens, o objetivo da sociologia é se voltar ao "problema da ordem”, ou seja, o que contribuiria para a manutenção de divisão de interesse que alimentasse a dinâmica todos contra todos. Entretanto, Giddens sugere outras vias de interpretação da dinâmica social da modernidade, em que se reformula essa ordem como um problema de ligação entre tempo e espaço. (GIDDENS, 1991).

Para Giddens, diferentemente das Ciências Naturais, as Ciências Sociais não conseguem canalizar suas propostas no meio social tão imediatamente, mas seu impacto prático está inteiramente envolvido ao que a modernidade é. As instituições modernas possuem uma finalidade globalizante, na medida em que as fontes da modernidade estão ligadas a uma separação de tempo e espaço, bem como a um desencaixe dos sistemas da sociedade, além de uma “[...] ordenação e reordenação reflexiva das relações sociais à luz das contínuas entradas (inputs) de conhecimento afetando as ações de indivíduos e grupos.” (GIDDENS, 1991, p. 21).

A respeito, a fragmentação da vida na era moderna conduz à reinterpretação do que é esse espaço, baseado numa cultura de mobilidade, de "territorializações e desterritorializações sucessivas". Isso significa que as comunicações têm como vetor principal atual as novas tecnologias de informação. (LEMOS, 2004). 
LYRA, José Francisco Dias da Costa; JOHANN, Lara Narjana. A leitura da dinâmica social moderna em um contexto de globalização: sistemas abstratos e o desencaixe entre tempo e espaço como produção de

Há um ritmo acelerado de mudanças na modernidade não característico nas sociedades tradicionais, em que o local está conectado ao global:

O advento da modernidade arranca crescentemente o espaço do tempo fomentando
relações entre outros "ausentes", localmente distantes de qualquer situação dada ou
interação face a face. Em condições de modernidade, o lugar se torna cada vez mais
fantasmagórico: isto é, os locais são completamente penetrados e moldados em termos
de influências sociais bem distantes deles. O que estrutura o local não é simplesmente
o que está presente na cena; a "forma visível" do local oculta as relações distanciadas
que determinam sua natureza. (GIDDENS, 1991, p. 22).

Assim, a modernidade inaugurou novas formas de integração e abriu espaço para a integração cada vez maior de diversas culturas, de modo que o local é determinado por influências globalizantes. As fronteiras deixaram de ser caracterizadas como barreiras impeditivas para a interação; as relações e os relacionamentos passaram a ser mutáveis e, facilmente, substituíveis. Hoje, não se faz necessário o estabelecimento de um território determinado: todos podem estar em qualquer lugar, independente do tempo, isto é, de não lugares intercambiáveis, de cidades globais (LEMOS, 2004).

Giddens sugere a separação entre tempo e espaço, que pode ser assim estabelecida somente nas sociedades modernas. A noção de que hoje leis podem ser manipuladas permite afirmar que há um desencaixe entre o tempo e o espaço, um conjunto de descontinuidades na construção e nas relações sociais do período moderno, desencaixe entre o tempo e o espaço, que permite a ausência do lugar como mediador das interações sociais, ou seja, separa-se o tempo e o espaço na dinâmica social moderna, pois se abre a possibilidade de as relações sociais acontecerem sem referenciar um lugar. Ainda, há a presença de uma organização racionalizada, e a dinâmica da alta modernidade conecta o local e o global de forma a mudar a vida da grande maioria das pessoas. (GIDDENS, 1991).

Como explicação para a noção desse desencaixe existente na modernidade é possível dizer que com o advento da invenção do relógio mecânico, a noção de que o tempo está diretamente ligado ao espaço ficou cada vez mais irrelevante. Em sociedades pré-modernas a referência de tempo era obtida através de calendário, bem como por via de marcadores espaciais do tempo. Após a universalização temporal através do relógio mecânico, com a expansão da modernidade, padronizaram-se os calendários e uniformizou-se a organização de tempo e espaço. Nesse sentido, todos os povos obedeceram a um calendário universal, e o tempo tornouse precondição de esvaziamento de espaço, já que a "coordenação através do tempo é a base do controle do espaço." (GIDDENS, 1991, p. 22). Tinha-se o controle, uma ordem pré-fixada, imutável, sólida, limitada. 
LYRA, José Francisco Dias da Costa; JOHANN, Lara Narjana. A leitura da dinâmica social moderna em um contexto de globalização: sistemas abstratos e o desencaixe entre tempo e espaço como produção de mal-estar e sofrimento

Como desencaixe, Giddens explica que as relações sociais da modernidade sofrem um deslocamento, de modo que se reestruturam de forma indefinida no tempo e no espaço, através de mecanismos abstratos denominados de fichas simbólicas, isto é "meios de intercâmbio que podem ser 'circulados' sem ter em vista as características específicas dos indivíduos ou grupos que lidam com eles em qualquer conjuntura particular" (GIDDENS, 1991, p. 25), e de sistemas peritos. O capitalismo, pela sua força simbólica, tornou-se o propulsor da transformação constante e alteração das visões de tempo e de espaço.

Como maior exemplo de ficha simbólica existente nas representações sociais está o dinheiro, cujo símbolo é fundamental para o desencaixe da atividade econômica da modernidade, bem como o sistema capitalista a principal presença na sociedade moderna. (GIDDENS, 1991). Para tanto, diferentemente de moedas de trocas (sal, madeira, pele), que eram fichas simbólicas de sociedades pré-modernas, em que se estabelecia uma mercadoria específica, o dinheiro como ficha simbólica facilita as trocas, sem exigir a igualdade das pessoas. Essa ficha simbólica liga um indivíduo a outro, sem estabelecer qualquer qualificação ou crença pessoal.

O dinheiro como ficha simbólica representa, em Giddens, débito ou crédito em meio a uma pluralidade de intercâmbios, podendo servir como um adiamento quando a troca de produtos não pode ser realizada naquele momento. Assim, se mostra capaz de viabilizar o distanciamento entre tempo e espaço:

O dinheiro, pode-se dizer, é um meio de retardar o tempo e assim separar as transações
de um local particular de troca. Posto com mais acurácia, nos termos anteriormente
introduzidos, o dinheiro é um meio de distanciamento tempo-espaço. O dinheiro
possibilita a realização de transações entre agentes amplamente separados no tempo e
no espaço. (GIDDENS, 1991, p. 27).

Os sistemas peritos, cuja significação representa excelência técnica ou competência para organizar as diversas áreas da sociedade (engenharias, medicina, ciências sociais, política, etc), são considerados mecanismos de desencaixe, pois “[...] removem as relações sociais das imediações do contexto" (GIDDENS, 1991, p. 31), já que fornecem garantias de expectativa com o distanciamento do tempo e o espaço. Importante observar que o indivíduo presencia diariamente tais sistemas. Além de os sistemas peritos significarem excelência técnica, por exemplo, quando se vai ao médico, eles vão além, pois integram tudo o quanto pode ser visto pelo homem. Casas, carros são compostos por diversos deles, e somente são explorados no dia a dia, pois há uma relação de confiança.

Eles ensejam uma confiança nas relações sociais, mas uma confiança que não necessariamente exija domínio do conhecimento, e sim uma confiança baseada "[...] na 
LYRA, José Francisco Dias da Costa; JOHANN, Lara Narjana. A leitura da dinâmica social moderna em um contexto de globalização: sistemas abstratos e o desencaixe entre tempo e espaço como produção de mal-estar e sofrimento

experiência de que tais sistemas geralmente funcionam como se espera que eles o façam" (GIDDENS, 1991, p. 31), isto é, uma confiança baseada em uma anterioridade, e ligada a uma segurança. A confiança está presente nas instituições da modernidade, eis que se manifestam nos sistemas de processos de formação da identidade, em sistemas abstratos, etc. Em contraponto com os aspectos positivos advindos com a globalização, aspectos negativos também ganharam espaço, entre eles a relativização da confiança, vez que a crença absoluta foi ultrapassada.

E isso fundamentalmente diferencia as relações sociais da modernidade, uma vez que, abandonando-se um sistema de crenças em deuses e espíritos, e criados os sistemas peritos, permite-se, ao menos que de forma presumida, que aqueles sistemas irão funcionar da forma que se espera. E não é diferente no sistema relacionado às relações íntimas de afeto. Se antes a segurança era condicionada às amarras religiosas, hoje, apesar de o amor ser relativizado, a segurança está presente e condicionada ao aprender a viver com o outro, e na incerteza de sua duração.

E, mais do que nunca, as relações pessoais estão intimamente ligadas à confiança: "A confiança pessoal, por conseguinte, tem que ser estabelecida através do processo de autoquestionamento: a descoberta de si tornar-se um projeto diretamente envolvido com a reflexividade da modernidade." (GIDDENS, 1991, p. 110). Questionar, duvidar e indagar são comportamentos que vieram em conjunto com a volatilidade das novas formas de relação.

Nas relações puras atuais, as âncoras externas do passado, como os motivos econômicos, casamento escolhido pelos pais, perpetuação da linhagem, ainda que existam de forma sazonal, no geral são substituídas pelo compromisso entre os parceiros. Isto é, "O casamento se torna mais e mais uma relação iniciada pela satisfação emocional que deriva do contato próximo com o outro, e enquanto essa satisfação persistir ele se mantém." (GIDDENS, 2002, p. 87).

Outra contribuição que Giddens realizou em seus estudos foi a reflexividade. Para ele, ela é a terceira maior característica da modernidade, pois as práticas sociais sofrem alterações constantemente através de uma renovação diante da informação trazida por essas mesmas práticas e ela permite uma maior noção de desencaixe entre o tempo e espaço. Essa reflexividade não é tão somente intrínseca a quem detenha certo grau de conhecimento, mas se estende a toda pessoa que adquira alguma noção no assunto diante de uma experiência anterior, e/ou que interprete algum fenômeno. (GIDDENS, 1991).

É característica marcante da modernidade, na medida em que com o desencaixe entre tempo e espaço a vida social se resguarda das influências do que vem pré-estabelecido, típico 
LYRA, José Francisco Dias da Costa; JOHANN, Lara Narjana. A leitura da dinâmica social moderna em um contexto de globalização: sistemas abstratos e o desencaixe entre tempo e espaço como produção de

das sociedades tradicionais. Aliás, as relações puras, conceito atribuído às relações de afeto e de amizade, demandam a reflexividade do indivíduo. Se na (alta) modernidade as relações demandam o compromisso recíproco entre os parceiros, “[...] quanto mais a relação depender de si mesma, tanto mais esse questionamento reflexivo será seu centro" (GIDDENS, 2002, p. 87). Isso quer dizer que a relação pura gera a recompensa de os parceiros estarem envolvidos, e se não correr seu curso normal, sem erros, estará ameaçada.

Ademais, ela incide nas relações afetivas, de modo que relacionar-se com alguém diz respeito ao conhecimento de que os indivíduos têm da alta taxa de divórcio, como explica Giddens:

\begin{abstract}
O conhecimento da alta taxa de divórcios pode afetar a própria decisão de se casar, bem como decisões sobre considerações relacionadas - o regime das propriedades etc. A consciência dos níveis de divórcio, além disso, é normalmente muito mais do que simplesmente a consciência de um fato bruto. Ele é teorizado pelo agente leigo de maneiras impregnadas pelo pensamento sociológico. Desta forma, virtualmente todos que consideram o casamento têm alguma idéia de como as instituições familiares vêm mudando, mudanças na posição social relativa e no poder do homem e da mulher, alterações nos costumes sexuais etc. - tudo isto entrando nos processos de mudança ulterior que reflexivamente informa. (GIDDENS, 1991, p. 43).
\end{abstract}

As observações feitas neste tópico irão permitir uma análise da aplicação do fenômeno da globalização e a dialética com o tempo-espaço fornecido pelos estudos de Giddens. Houve, através das constantes e marcantes alterações societárias, considerável mutação na compreensão e na determinação de tempo e espaço; entretanto, mesmo que tal situação trouxe a benéfica possibilidade de aproximação, o seu desencaixe é multifacetado, pois, em contrapartida tornou as relações mais duvidosas, instaurando a instabilidade relacional. A seguir, será verificado se essa dialética de tempo e espaço com o fenômeno da globalização tem contribuído para a produção de mal-estar e cansaço sociais.

\title{
40 mal-estar e o cansaço como experiências do risco do mundo contemporâneo.
}

Existe uma relevante lista de obras que permite uma reflexão acerca das características da modernidade. Obras que realizam um diagnóstico social a partir de diversos aspectos, com a influência do fenômeno da globalização. Se Giddens afirma que qualquer estrutura social não se exime de sofrer com as mudanças impostas pela globalização, então diversas são as maneiras de abstração dessa influência.

É nesse ponto que é digno de citar a importante contribuição que Christian Dunker traz ao debate. Em seus escritos, o autor procura compreender como as formações socioculturais produzem ou tendem a produzir sofrimentos. Em suas discussões na área da psicanálise, volta- 
LYRA, José Francisco Dias da Costa; JOHANN, Lara Narjana. A leitura da dinâmica social moderna em um contexto de globalização: sistemas abstratos e o desencaixe entre tempo e espaço como produção de

se a defender a existência do sofrimento como expressão de um não reconhecimento e o malestar passa a existir quando há a perda de experiência do indivíduo. (DUNKER, 2015).

A racionalidade econômica inaugurada com a globalização determina uma contraposição da dinâmica social atual com a dos tempos pré-modernos. E isso se intensifica se for trazido à discussão a virtualização. Como ferramenta de controle das ações do quotidiano o controle remoto viabilizado pela tecnologia dos aparelhos de telefonia móvel possibilita a conexão, mas não significa que enriquece a comunicação nem garante o seu entendimento. Se a comunicação, por si só, não chega a mais pessoas além das presentes em uma determinada situação, e se ela nem sempre é compreendida face a face, é pouco menos provável por meio da Cibercultura (LEMOS, 2004).

Indivíduos são convidados a experimentar uma nova forma de socialização, oportunizada por sistemas de desencaixe e mediada por redes sociais e com isso uma nova forma de solidão entra em atividade. Entre presença e ausência, os sistemas de desencaixe, assim nomeados por Giddens, terminam por desqualificar atividades habituais. Não se pode olvidar de observar que o dinamismo decorrente da tecnologia e do afastamento entre tempo e espaço torna evidente um risco. Isto é, a aceitação de que o curso das coisas pode estar sujeito a contingências. (GIDDENS, 2002). Para tanto, se não há garantias em qualquer atividade humana, seja com a ciência ou com a tecnologia, é preciso compreender e aceitar a finitude das coisas.

A alta modernidade é caracterizada pelas possibilidades de estilos de vida oferecidas ao sujeito. Como explica Giddens, nas sociedades tradicionais a tradição era imposta ao indivíduo, juntamente com um conjunto de crenças e formas de agir específicas de uma comunidade. (GIDDENS, 2002). Atualmente, são nos postos em oferta diversos estilos de vida carregados por influências de grupos ou por circunstâncias econômicas, isto é, uma pluralidade de escolhas dissociadas de uma tradição. Entretanto, nos tira a certeza da escolha, quer dizer, um risco característico pela incerteza do futuro. Nesse sentido, os sistemas abstratos e os sistemas peritos têm importância na característica da sociedade moderna:

A reflexividade da modernidade opera numa situação de certeza cada vez maior, mas numa situação de dúvida metódica. Só podemos confiar mesmo nas autoridades mais fidedignas, até "nova ordem"; e os sistemas abstratos que tanto penetram na vida cotidiana normalmente oferecem múltiplas possibilidades em vez de fornecer guias ou receitas fixas de ação. Sempre podemos nos voltar para os peritos, mas eles próprios muitas vezes estão em desacordo sobre teorias e diagnósticos práticos. (GIDDENS, 2002, p. 82). 
LYRA, José Francisco Dias da Costa; JOHANN, Lara Narjana. A leitura da dinâmica social moderna em um contexto de globalização: sistemas abstratos e o desencaixe entre tempo e espaço como produção de mal-estar e sofrimento

É claro que os sistemas abstratos trouxeram grandes avanços. O sistema monetário, como próprio Giddens afirma, foi fundamental para o desencaixe da atividade moderna, da mesma forma que o sistema capitalista se expandiu, de modo que a ficha simbólica representada pelo dinheiro tornou-se essencial para as atividades modernas. (GIDDENS, 1991). O despertar capitalista pelo consumo exacerbado em conjunto com a mutação da determinação de tempo e espaço trouxe consigo outras inseguranças e incertezas para as relações sociais, possibilitando concluir que os sistemas abstratos são multifacetados, pois ora são benéficos numa confiança de que seguirão seu curso, conforme planejado, ao mesmo tempo que carregam riscos quanto ao seu fluxo.

A alta modernidade viabilizou a conexão entre os indivíduos por meio de diversos sistemas abstratos, como é o caso do dinheiro. Entretanto, a incidência de sistemas abstratos demanda confiança e cria riscos que o indivíduo é incapaz de suportar. E ainda, os sistemas abstratos tendem a desqualificar a vida cotidiana, fragmentando as formas preexistentes da vida tradicional. No processo de desencaixe entre tempo e espaço, eles originam uma perda, segundo Giddens, que não se pode controlar diante de um sistema global, pois suas interferências ocorrem incisivamente nas formas de sociedades com características tradicionais. (GIDDENS, 2002).

A relação de confiança estabelecida nas culturas pré-modernas era tida com importância demasiada em contextos localizados. Primeiro, com relação ao sistema de parentesco, de forma que, mesmo havendo instabilidade entre pessoas ligadas à consanguinidade, essas ligações permitiam a fé no cumprimento de obrigações. Segundo, a confiança ao contexto local em que se estabelecia uma comunidade é o que determinava relações entrelaçadas entre os indivíduos. Terceiro, a crença na cosmologia religiosa proporcionava (e ainda hoje proporciona) “[...] interpretações morais e práticas da vida pessoal e social, bem como do mundo natural, o que representa um ambiente de segurança para o crente" (GIDDENS, 1991, p. 93). E então, outra confiança característica das antigas sociedades foi a tradição, na medida em que sustenta a confiança de continuidade do que se passou, ao presente e ao futuro.

Diferentemente da modernidade, em que as relações de parentesco, apesar de serem importantes, não são mais consideras condutores de laços sociais. A segurança conseguida pela fixação de um lugar foi tomada pelo desencaixe e pelo distanciamento entre o tempo e o espaço. Nessa linha, há o entrelaçamento entre o local e o global e, embora os sentimentos de ligação com um lugar ainda se mostram presentes, ficam desencaixados, pois “[...] não expressam apenas práticas e envolvimentos localmente baseados, mas se encontram também salpicados de influências muito mais distantes." (GIDDENS, 1991, p. 98). Ainda, a grande maioria das 
LYRA, José Francisco Dias da Costa; JOHANN, Lara Narjana. A leitura da dinâmica social moderna em um contexto de globalização: sistemas abstratos e o desencaixe entre tempo e espaço como produção de

situações da vida social é incompatível com qualquer influência religiosa, eis que o conhecimento reflexivo contribuiu para tanto.

Mas uma insegurança ontológica surge com a modernidade:

\begin{abstract}
A confiança em sistemas abstratos é a condição do distanciamento tempo-espaço e das grandes áreas de segurança na vida cotidiana que as instituições modernas oferecem em comparação com o mundo tradicional. As rotinas que estão integradas aos sistemas abstratos são centrais à segurança ontológica em condições de modernidade. Contudo, esta situação cria também novas formas de vulnerabilidade psicológica, e a confiança em sistemas abstratos não é psicologicamente gratificante como a confiança em pessoas o é. (GIDDENS, 1991, p. 102).
\end{abstract}

Confiar em sistemas abstratos, portanto, significa que há chances de mudança ou erro naquele próprio sistema. Como dito, mesmo que eles funcionem corretamente, estão sujeitos a falhas e a mutações, o que é característica dos tempos modernos. Tal situação acaba por provocar ao indivíduo sentimentos compostos de sofrimentos, de angústias, de vazios; muito em razão das incertezas das relações sociais modernas e da alta modernidade, pois abandonase uma única crença e passa-se a viver pelas relações de confiança.

O indivíduo busca confiança tantos em sistemas abstratos como nas próprias relações interpessoais. Assim, a busca pela construção do eu é realizada por meio do que Giddens menciona como projeto reflexivo, buscando encontrar sua própria identidade através dos sistemas abstratos. Segue ele, almejando a autossatisfação, em defesa de um mundo externo e globalizante a que não tem controle. Se sujeita à globalização de riscos, seja por ameaças de guerras, expansão de eventos contingentes, riscos ambientais etc. (GIDDENS, 1991, p. 111112).

E o risco característico das sociedades pós-tradicionais pode sugerir novas formas de sofrimento. Como exemplo, a modernidade instaurou um risco que reflete o sofrimento pela (in) capacidade de estar só. E sem ressalvas, ora a solidão representa maturidade psicológica, ora reflete uma exclusão social, como uma recusa de reconhecimento. Do mesmo modo, as transformações culturais, com a homogeneização e instituição de padrões de comportamento são características do estilo de vida atual. (DUNKER, 2017, p. 19; 78). O risco se estabelece na incerteza de um relacionamento, na dúvida da escolha do futuro profissional, ao se optar pela viagem dos sonhos, e até mesmo na incerteza quanto à consequência de leis impostas.

Nessa dinâmica das representações sociais, como um sintoma da modernidade, toma-se de empréstimo a lógica do condomínio. Com o objetivo de formar uma comunidade de integração, com seu próprio sistema de segurança, sua própria área de lazer, o condomínio segrega o que não está dentro de seus muros. Uma modalidade de isolamento é vista nessa 
LYRA, José Francisco Dias da Costa; JOHANN, Lara Narjana. A leitura da dinâmica social moderna em um contexto de globalização: sistemas abstratos e o desencaixe entre tempo e espaço como produção de

forma de se estabelecer em sociedade. Essa lógica de condomínio se percebe em diversas instituições sociais: a lei, o tratamento de patologias, o meio social, etc. (DUNKER, 2015).

O mal-estar pode ser entendido como um “[...] sentimento existencial de perda de lugar, a experiência real de estar fora de lugar". O verbo estar é encontrado em frases do dia-a-dia: quando se é perguntado "como está", significaria também perguntar "onde se está", para refletir esse sentimento de pertencimento, de que somos no mundo. Assim, a mais forte sensação de mal-estar seria a de um sentimento de não estar, de uma desconexão com o pertencimento, ou um sentimento de deslocamento. O mal-estar varia conforme a realidade social e a cada época. Nesse sentido, as relações amorosas, de amizade e profissionais ocorrem com o indivíduo olhando isso acontecendo no mundo, mas sente que está fora dele. (DUNKER, 2017, p. 77).

Por isso, o mal-estar se reflete em sentimentos de desconexões tanto quando se está fora (experiência de indeterminação do sujeito, deserto), quanto quando se está dentro (condomínios, leis, representações sociais, etc.). (DUNKER, 2015, p. 198-199). Dessa forma, o que se estabelece com a modernidade é o estranhamento: no que toca aos condomínios como também ao que confere as relações inter e intra subjetivas se reflete como o homem se afastou das relações fora e além de si. Assim, a não determinação:

[...] o mal-estar não é a própria angústia, mas liga-se a um déficit de percepção da angústia que possui efeitos de inibição e se qualifica como torturante, o tormento, a angústia que se repete, que se remói, a angústia cuja causa, razão ou motivo não se discerne muito bem, pode ser então como predicado do mal-estar.(DUNKER, 2015, p. 205).

Existe, pois, uma conexão entre os sistemas sociais e o sofrimento. Sofrimento, porque se manifesta como expressão de um não reconhecimento. $\mathrm{O}$ sofrimento está ligado ao malestar, eis que existe a possibilidade de um mal estar corporal, como é o caso de um sintoma e também, por outro lado, se permite falar em um mal-estar moral que se traduz em uma experiência coletiva ou individual de sofrimento. (DUNKER, 2015, p. 196).

Dunker classifica o sofrimento de acordo com três condições: a primeira delas é que o sofrimento pode ser pensado sob o viés de uma teoria de reconhecimento, pois se permite reconhecer quais os graus do sofrimento são suportáveis e necessários, e como esses graus são definidos politicamente em cada época, separando o suportável do patológico; como segunda condição, entende-se que uma narrativa estrutura o sofrimento; e, como terceira condição, o autor refere que a experiência do sofrimento é envolvida pelo que se denomina de transitivismo - isto é, "processos de indeterminação de sentido e de inversão de significação" (DUNKER, 2015, p. 219), cujo exemplo mais conhecido é o de uma agressão praticada por uma criança, 
LYRA, José Francisco Dias da Costa; JOHANN, Lara Narjana. A leitura da dinâmica social moderna em um contexto de globalização: sistemas abstratos e o desencaixe entre tempo e espaço como produção de

em que ela própria - agressora - sofre o efeito, confundindo a relação entre praticante e agredido.

Mencionando os trabalhos de Axel Honneth, Dunker busca introduzir o sofrimento na esfera do reconhecimento, e explica que quando o reconhecimento da esfera do amor, da estima social e do direito se desentrelaçam, surge o conceito de sofrimento por indeterminação. E há um ponto de preocupação quando se perde o elo entre responsabilidade (amor), segurança (esfera da estima social) e justiça (direito), cujas concepções tornaram-se um produto. (DUNKER, 2015).

O sofrimento de indeterminação está condicionado à capacidade de reconhecimento recíproco da liberdade do outro. Da mesma forma, ele procede de uma "rejeição da realidade social e na autonomização ou na absolutização de modelos incompletos de liberdade" (DUNKER, 2015, p. 227). Nos tempos atuais, de ascensão do consumo, de banalização e desorganização familiar, dentre outros fatos sociais, tem prevalecido o sofrimento em que o sujeito sofre por não conseguir tornar-se um indivíduo ou sofre por imaginar somente a realização em tornar a ser um. Esse mal-estar, que condiciona o modo de estar no mundo, exprime as condições da modernidade. Esse estilo de vida transfere às relações íntimas um princípio de desempenho, de resultados sendo avaliados, de análise dos riscos e segurança. (DUNKER, 2017).

É preciso buscar uma melhor interpretação das relações sociais, bem como interpretar como o indivíduo, em sua capacidade reflexiva, experimenta a dinâmica do local e global e se utiliza dela para construir suas relações interpessoais e a relação consigo mesmo. A confiança entre as relações se tornou uma meta relacional, pois a confiabilidade no outro proporciona a sensação de segurança que outrora era proporcionada pela crença pré-fixada do já determinado. Ademais, pode-se notar que reconhecer e ser reconhecido são questões atuais vez que, após ser alterada a determinação de tempo e espaço, onde a aproximação e o distanciamento trocaram as significações, houve um distanciamento nas relações e a ausência de reconhecimento acaba por intensificar o sofrimento no indivíduo.

\section{Conclusão}

O presente trabalho foi realizado com o objetivo de estudar as representações sociais no mundo contemporâneo, fazendo uma leitura da modernidade ou alta modernidade, dos sistemas abstratos e como eles podem refletir nas relações humanas. E como essa dinâmica moderna pode contribuir para novas formas de mal-estar e sofrimento. 
LYRA, José Francisco Dias da Costa; JOHANN, Lara Narjana. A leitura da dinâmica social moderna em um contexto de globalização: sistemas abstratos e o desencaixe entre tempo e espaço como produção de

Primeiramente, foi abordado o fenômeno da globalização, e suas implicações pelo capitalismo e de uma cybercultura. A globalização permitiu o alargamento das relações sociais e a superação dos limites territoriais, fez emergir uma convergência a novas formações culturais e de identidade. Por outro lado, favoreceu por meios digitais a produção e o consumo. A globalização trouxe mudanças significativas, vez que seu alcance não pode ser medido ou limitado; alterou assim as relações sociais e as perspectivas sobre tempo e espaço, alterando as formas de aproximação e distanciamento.

No segundo capítulo, se buscou trazer as explicações realizadas por Anthony Giddens com relação à (alta) modernidade. O processo de modernização implica alterações nas esferas objetivas e subjetivas, e isso vem representado através de uma dialética de desencaixe entre tempo e espaço, e exige uma capacidade reflexiva do indivíduo, diferente do período prémoderno. O processo de desencaixe da modernidade reflete a forma de nos posicionarmos e relacionarmos na construção do "eu" e nas relações interpessoais.

No terceiro capítulo, foi trazido ao debate observações acerca desse processo de modernização e as novas formas de como o indivíduo experimenta o mundo, uma nova forma mental de relacionamento depois de o surgimento da modernidade. São consequências da modernidade, ou reflexos da evolução humana a partir de uma concepção do global de dinâmica entre tempo e espaço e o risco da geral incidência e dos riscos trazidos dos e pelos sistemas abstratos na vida cotidiana. A modernidade e a forma como nos relacionamos com ela fez emergir uma nova forma de intimidade, de ressignificação do relacionamento do indivíduo com os demais e com ele mesmo, apoiado na insegurança que ele sente frente à dinâmica social moderna.

Portanto, se permitiu responder à pergunta do presente ensaio, na medida em que se pode perceber um mal-estar contemporâneo, resultante de uma indeterminação, ou seja, o sofrimento ocorre porque o indivíduo não consegue sentir pertencido a um lugar, sofre por não conseguir uma forma de vida contemplativa, diante das exigências impostas pela liquidez da sociedade de consumo e de desempenho e de maximização da produção. Muito provavelmente, os novos sofrimentos ocorrem em razão do indivíduo não conseguir acompanhar, no mesmo ritmo, as mudanças sociais.

Reflexo da globalização é o dinamismo das relações sociais, perdeu-se a confiabilidade única do sistema, vez que se vive uma época no qual tudo é mutável, substituível. Em meio às incertezas da modernidade a busca incessante pelo reconhecimento, pois através deste ocorre a satisfação do indivíduo pela compreensão de que pertence ao lugar. 
LYRA, José Francisco Dias da Costa; JOHANN, Lara Narjana. A leitura da dinâmica social moderna em um contexto de globalização: sistemas abstratos e o desencaixe entre tempo e espaço como produção de mal-estar e sofrimento

\section{Referências}

ALMEIDA, Marco Antonio de. Mediações Tecnossociais e mudanças culturais na sociedade da informação. In CASTRO, Ana Lúcia de. Cultura contemporânea, identidades e sociabilidades: olhares sobre corpo, mídia e novas tecnologias [online]. Cultura Acadêmica. São Paulo: Editora Unesp, 2010.

BAUMAN, Zygmunt. Globalização, as consequências humanas. Rio de Janeiro: Zahar editora, 1999.

BAUMAN, Zygmunt. A sociedade individualizada: vidas contadas e histórias vividas. Rio de Janeiro: Zahar editora, 2008.

DUNKER, Christian Ingo Lenz. Mal-estar, sofrimento e sintoma: uma psicopatologia do Brasil entre muros. 1 Ed. São Paulo: Editora Boitempo, 2015.

DUNKER, Christian Ingo Lenz. Reinvenção da intimidade: políticas do sofrimento cotidiano. São Paulo: Editora Ubu, 2017.

GIDDENS, Anthony Modernidade e identidade. Rio de Janeiro: Jorge Zahar Editor, 2002.

GIDDENS, Anthony. As consequências da modernidade. São Paulo: Editora Unesp, 1991.

GIDDENS, Anthony. Mundo em descontrole.3 ed. Rio de Janeiro: Editora Record, 2007.

GIDDENS, Anthony. O mundo na era da Globalização. 6. ed. Lisboa: Editora Presença, 2006.

LEMOS, André. Cibercultura e mobilidade: a era da conexão. Razon y palabra, v. 41, 2004.

LÉVY, Pierre. Cybercultura. São Paulo: Editora 34, 1999.

ORTIZ, Rocío Rueda. Cibercultura: metáforas, prácticas sociales y colectivos en red. Nómadas (Col), n. 28, p. 8-20, 2008. Disponível em:

http://bibliotecavirtual.clacso.org.ar/ar/libros/colombia/iesco/nomadas/28/01-cibercultura.pdf. Acesso em: 03 nov. 2021.

SALDANHA, Alexandre Henrique Tavares; SALDANHA, Paloma Mendes. Direitos autorais, liberdade de expressão e cultura de participação na internet. Direitos Culturais, Santo Ângelo, v. 12, n. 27, p. 33-46. Disponível em

http://srvapp2s.urisan.tche.br/seer/index.php/direitosculturais/article/view/2198/1055. Acesso em: 07 abr. 2020. 